\title{
A systematic review of transarterial embolization versus emergency surgery in treatment of major nonvariceal upper gastrointestinal bleeding
}

This article was published in the following Dove Press journal:

Clinical and Experimental Gastroenterology

16 April 2014

Number of times this article has been viewed

\section{Andrew D Beggs' \\ Mark P Dilworth' \\ Susan L Powell ${ }^{2}$ \\ Helen Atherton ${ }^{3}$ \\ Ewen A Griffiths ${ }^{4}$}

'Academic Department of Surgery, School of Cancer Sciences, University of Birmingham, ${ }^{2}$ Department of Geriatric Medicine, Heart of England NHS Foundation Trust, Solihull Hospital, Birmingham, ${ }^{3}$ Department of Primary Health Care Health Sciences, University of Oxford, Oxford, ${ }^{4}$ Department of Upper Gastrointestinal Surgery, University Hospitals Birmingham NHS Foundation Trust, Birmingham, UK
Correspondence: Ewen A Griffiths Department of Upper Gastrointestinal Surgery, Area 6, Level 7, University Hospitals Birmingham NHS Foundation Trust, Queen Elizabeth Hospital, Birmingham, BI5 2TT, UK

Tel +44 I2I3 7/5882

$\mathrm{Fax}+44$ I2I3 715596

Email ewen.griffiths@uhb.nhs.uk
Background: Emergency surgery or transarterial embolization (TAE) are options for the treatment of recurrent or refractory nonvariceal upper gastrointestinal bleeding. Surgery has the disadvantage of high rates of postoperative morbidity and mortality. Embolization has become more available and has the advantage of avoiding laparotomy in this often unfit and elderly population.

Objective: To carry out a systematic review and meta-analysis of all studies that have directly compared TAE with emergency surgery in the treatment of major upper gastrointestinal bleeding that has failed therapeutic upper gastrointestinal endoscopy.

Methods: A literature search of Ovid MEDLINE, Embase, and Google Scholar was performed. The primary outcomes were all-cause mortality and rates of rebleeding. The secondary outcomes were length of stay and postoperative complications.

Results: A total of nine studies with 711 patients (347 who had embolization and 364 who had surgery) were analyzed. Patients in the TAE group were more likely to have ischemic heart disease (odds ratio $[\mathrm{OR}]=1.99 ; 95 \%$ confidence interval $[\mathrm{CI}]: 1.33,2.98 ; P=0.0008 ; P^{2}=67 \%$ [random effects model]) and be coagulopathic (pooled OR $=2.23 ; 95 \%$ CI: 1.29, 3.87; $P=0.004$; $I^{2}=33 \%$ [fixed effects model]). Compared with TAE, surgery was associated with a lower risk of rebleeding $\left(\mathrm{OR}=0.41 ; 95 \% \mathrm{CI}: 0.22,0.77 ; P<0.0001 ; P^{2}=55 \%\right.$ [random effects] $)$. There was no difference in mortality (OR $=0.70 ; 95 \%$ CI: $0.48,1.02 ; P=0.06 ; P=44 \%$ [fixed effects]) between TAE and surgery.

Conclusion: When compared with surgery, TAE had a significant increased risk of rebleeding rates after TAE; however, there were no differences in mortality rates. These findings are subject to multiple sources of bias due to poor quality studies. These findings support the need for a well-designed clinical trial to ascertain which technique is superior.

Keywords: meta-analysis, radiology, surgery, interventional radiology, GI hemmorhage

\section{Introduction}

Nonvariceal upper gastrointestinal (GI) bleeding (NVUGB) is a common medical emergency requiring hospital admission. Improvements in endoscopic hemostatic techniques and medication have meant that only $13 \%$ of patients develop rebleeding. ${ }^{1}$ Rebleeding is a significant predictor of risk for mortality and can often be salvaged by further therapeutic endoscopy. ${ }^{2}$ Consequently the requirement for emergency surgery has dropped from approximately $20 \%$ in the 1970 s to less than $2 \%$ in the present day. ${ }^{1}$ Patients who fail endoscopic hemostasis are often elderly with multiple comorbidities. Consequently these patients are at high risk for morbidity and mortality after emergency surgery. Mortality ranges from $10 \%-30 \%$ following operative management. ${ }^{1,3}$ 
Although the technique of stopping bleeding from upper GI tract lesions with transarterial embolization (TAE) was first described in 1972, ${ }^{4}$ it has only recently become more available. Critics in the past have expressed concern about TAE being poorly available, especially out of routine work hours. However, a recent survey has shown good availability, principally in larger teaching hospitals. ${ }^{5}$ It is especially used in patients with multiple medical comorbidities who are poor candidates for surgery. Developments in interventional radiological equipment and techniques, especially low-prolife catheter systems and advanced embolic agents, such as microcoils, chemical particles, and cyanoacrylate glues, have allowed embolization to have a high success rate in achieving hemostasis. ${ }^{6}$ The principal advantage of interventional radiology is the avoidance of major emergency surgery in a critically ill and unstable patient.

The published guidelines for managing refractory NVUGB have evolved over time. The British Society of Gastroenterology guidance published in 2002 recommended that active NVUGB that cannot be stopped by endoscopic intervention needs an urgent surgical operation. ${ }^{7}$ The Scottish Intercollegiate Guidelines Network 2008 guidance $^{8}$ suggests that NVUGB not controlled by endoscopy should be treated by repeat endoscopic treatment, selective arterial embolization, or surgery (grade D evidence). ${ }^{8}$ The International Consensus Upper Gastrointestinal Bleeding Conference Group published guidelines in 2010 recommending that patients with active NVUGB that cannot be stopped by endoscopic intervention should be considered for embolization therapy. ${ }^{9}$ The 2012 UK National Institute of Clinical Excellence (NICE) guidance recommends that unstable patients who rebleed after endoscopic treatment should be offered interventional radiology and that if this is not promptly available, the patient should be referred urgently for surgery. ${ }^{10}$ This latest NICE guidance is based on very low-quality evidence from observational studies and the recommendation of the guidelines development group.

Given the fact that all NVUGB guidance for severe and refractory bleeding relies on evidence of limited quality, highquality randomized trials are desperately required. However, these would be difficult logistically and are unlikely to be feasible for a variety of reasons. Because of the paucity of trials, we decided to perform a systematic review and meta-analysis of the literature comparing TAE to emergency surgery.

\section{Methods}

\section{Study identification}

We searched Ovid MEDLINE (1946 to October 1, 2013), Embase (1980 to 2013 week 17), and Google Scholar. The medical subject headings (MeSH) search terms and keywords used were ("gastrointestinal bleeding" or "GI bleeding") and ("embolization" or "embolization") and "surgery". The search was performed in May 2013. Lists of citations were reviewed independently by three authors (ADB, EAG, and MPD). Studies were retrieved, and relevant studies were identified via screening of their title and abstracts. The bibliographies of identified studies were hand searched, and any further relevant studies were included.

\section{Inclusion and exclusion criteria}

Participants in studies had to be adults undergoing either TAE or surgery, for the treatment of NVUGB that had failed endoscopic management. Only studies (randomized controlled trial [RCT], prospective observational or retrospective studies) that directly compared the two techniques were considered for further evaluation. Excluded were case reports, letters, and reviews containing no original data. The studies were selected by two authors (ADB and EAG), and disagreements were resolved by consensus discussion. Abstracts of studies were reviewed for relevance by two reviewers (ADB and $\mathrm{EAG}$ ), and nonrelevant studies were not included in the analysis. The full text of selected studies was then examined to check for relevance, and studies were discarded if they were not relevant. In case of disagreement, the whole paper was reviewed and a consensus decision reached (Figure 1 and Table 1).

\section{Outcomes}

The baseline characteristics of the groups (age, comorbidity, and hemoglobin levels) were compared. The primary outcomes were rebleeding rates and all-cause mortality. The secondary outcomes were rates of medical postoperative complications (pneumonia, myocardial infarction [MI], kidney injury, and stroke) and length of hospital stay.

\section{Data extraction and quality assessment}

Articles that met the criteria for inclusion underwent data extraction using a Microsoft ${ }^{\circledR}$ Excel $^{\circledR}$ spreadsheet (version 2010; Microsoft Corporation, Redmond, WA, USA). The data extracted were as follows: study; authors; journal; year of publication; mortality; rebleeding; length of stay; rates of pneumonia, MI, stroke and renal failure; preprocedure hemoglobin; age; American Society of Anesthesiology (ASA) classification status; and comorbidities (ischemic heart disease, diabetes, renal disease, respiratory disease, coagulopathy). Data were imported into Review Manager (RevMan) Version 5.2 (Nordic Cochrane Centre, Copenhagen, Denmark). 


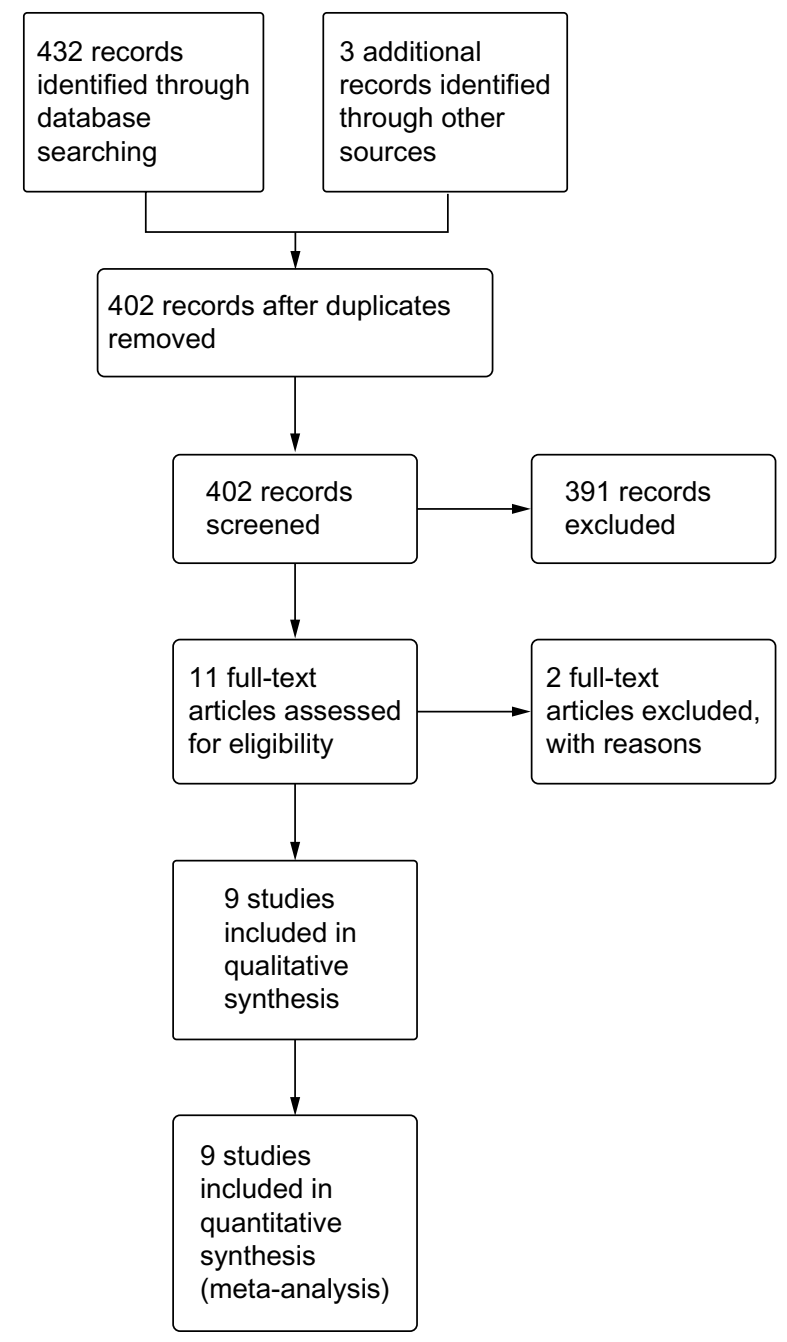

Figure I Flowchart showing study selection.

The quality of all nonrandomized observational studies was assessed using the Newcastle-Ottawa Scale. ${ }^{11}$ This was assessed by examining three factors: method of patient selection, comparability of the study groups, and number of outcomes reported. Two reviewers independently allocated scores for study quality, and disagreement was resolved by reexamining the relevant paper until consensus was achieved. The maximum score was nine stars, and high-quality studies usually had greater than seven stars.

\section{Statistical analysis}

Measures of treatment effect were chosen pragmatically, based on the available literature and clinically relevant end points. The primary outcomes were overall mortality and rates of rebleeding. The secondary outcomes were ASA score, age of patient, length of stay, rates of pneumonia/ $\mathrm{MI} /$ renal failure/stroke, age, preoperative hemoglobin levels, and rates of preoperative ischemic heart disease/ renal disease/respiratory disease/coagulopathy. All models were fixed-effects, unless significant statistical heterogeneity ( $>50 \%$ was noted), when a random effects model was used. Statistical heterogeneity was determined using the $I^{2}$ estimates, and was defined as low $(<25 \%)$, moderate $(25 \%-50 \%)$, and high $(>50 \%)$. Publication bias was assessed by funnel plots and the Egger Test (data was imported into Stata ${ }^{\circledR} 12$ [version 12.1; StataCorp LP, College Station, TX, USA] to carry this out). A sensitivity analysis was carried out by taking studies out of each model sequentially, the largest study being removed first. All the statistical analyses were performed with Review Manager 5.2 and Stata 12.1.

\section{Results}

This review was reported in accordance with the guidelines of the quality of reporting of meta-analyses (preferred reporting items for systematic reviews and meta-analyses [PRISMA] $)^{12}$ statement.

\section{Study identification, selection and quality assessment:}

In total, 432 studies were identified through database searching, and three additional studies were found through other sources. After the removal of duplicates, 402 records were left for screening. Of these 402, nine studies were taken forward and 393 excluded from the analysis (Figure 1). In total, nine studies, with a total of 711 patients, were examined, with 347 patients in the TAE group and 364 in the surgery group. Assessment of the quality of the studies revealed that all the studies were adequate according to the Newcastle-Ottawa Scale (Table S1). They mainly comprised of retrospective cohort data, with no age, sex or comorbidity matching, due to the limitations of the type of study being undertaken. It could be argued that there was severe selection bias in these studies as patients with greater comorbidity were selected for TAE. Data completeness was reasonable; however, comparability was poor because of the lack of selection of patients to standardize outcomes. No randomized studies were identified in our literature search.

\section{Publication bias}

Presence of publication bias was assessed separately for each outcome by visual inspection of funnel plots (Figures S1 and S2) and the Egger test. In order to perform the Egger test, data were imported into Stata 12.1. No evidence of publication bias was identified. 


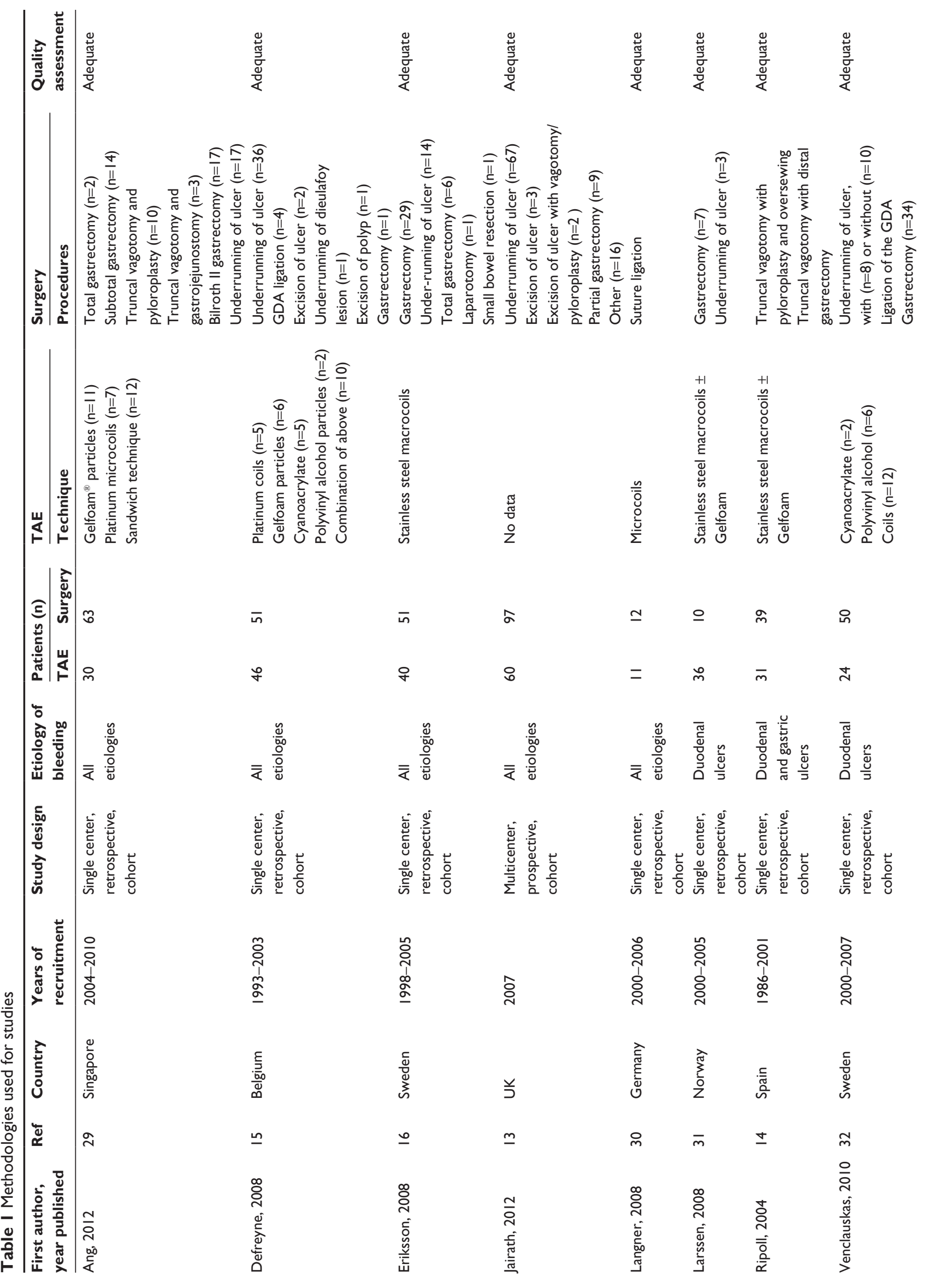




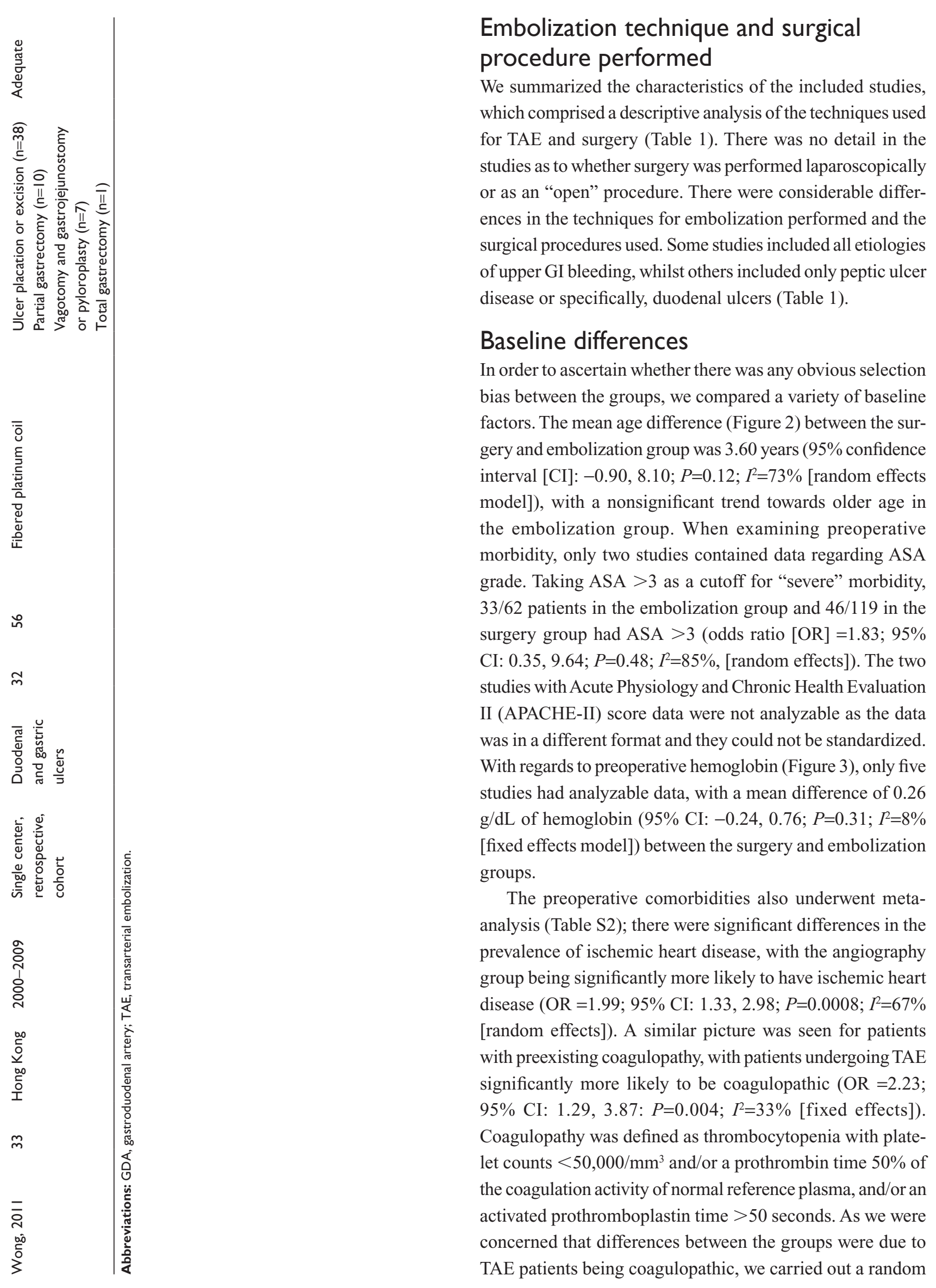




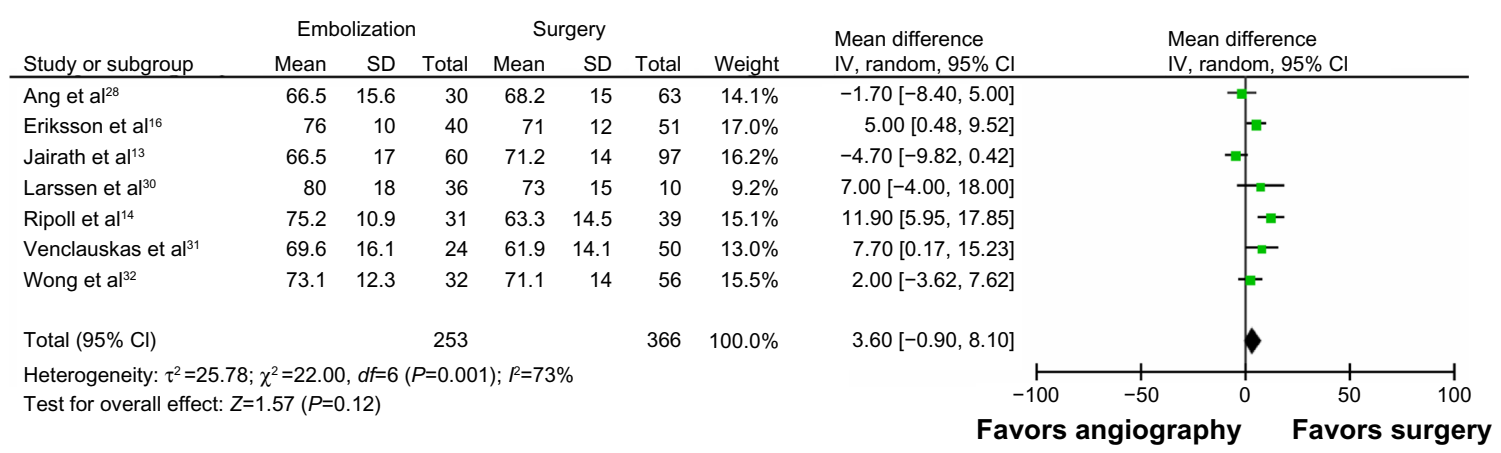

Figure 2 Forest plot of mean age, between the embolization and TAE groups.

Abbreviations: $\mathrm{Cl}$, confidence interval; $d f$, degrees of freedom; IV, initialization vector; SD, standard deviation; TAE, transarterial embolization.

effects meta-regression using summary-level data (Stata 12.1) of rebleeding rates and mortality, using coagulopathy as a covariate. No significant interaction between coagulopathy and mortality/rebleeding rates was seen (data not shown). There were no differences between the groups for diabetes, renal disease, or respiratory diseases.

\section{Clinical outcomes}

\section{Primary outcomes}

For mortality, there were 61 deaths in the angiography group and 101 in the surgery group (Figure 4), with no difference between the two groups in terms of mortality ( $\mathrm{OR}=0.70$; 95\% CI: $0.48,1.02 ; P=0.06 ; P^{2}=44 \%$ [fixed effects]). There was moderate between-study statistical heterogeneity, possibly because of the variable definition of mortality used in the studies. The Jairaith et al ${ }^{13}$ and Ripoll et a ${ }^{14}$ studies both quoted "in hospital" mortality rates; the remainder quoted 30 -day mortality rates. When the Jairath et $\mathrm{al}^{13}$ and Ripoll et $\mathrm{al}^{14}$ studies were considered together, excluding the other studies, there was no mortality difference between surgery and embolization ( $\mathrm{OR}=2.32 ; 95 \% \mathrm{CI}: 0.87,6.16 ; P=0.899$; $I^{2}=50 \%$ [random effects]).

For rebleeding rates, there were 78 events in the angiography group and 45 events in the surgery group (Figure 5), with surgery showing a reduced odds of rebleeding compared with TAE $\left(\mathrm{OR}=0.41 ; 95 \%\right.$ CI: $0.22,0.77 ; P=0.006, I^{2}=53 \%$ [random effects]). Destinations for patients failing initial TAE therapy are shown in Table S3.

\section{Secondary outcomes}

For length of stay, the mean difference between surgery and angiography was 0.75 days ( $95 \% \mathrm{CI}:-2.36,3.85$ days; $P=0.64 ; I^{2}=56 \%$ [random effects]), nonsignificantly favoring angiography; however, only seven studies out of the nine had data that was meta-analyzable for this variable (data not shown).

For other markers of postoperative morbidity, only two studies quoted rates of pneumonia, MI, renal failure, and stroke. In total, there were 92 complications in the embolization group and 81 in the surgery group $(\mathrm{OR}=0.93$; 95\% CI: $0.60,1.40 ; P=0.72 ; P^{2}=0 \%$ [fixed effects]). For pneumonia, there were 18 events in the angiography group and 34 events in the surgery group (data not shown), but no overall effect for either intervention was seen (OR $=1.07 ; 95 \% \mathrm{CI}$ : $0.25,4.53 ; P=0.93 ; I^{2}=77 \%$ [random effects]).

For MI, there were eleven events in the angiography group and 15 events in the surgery group, with no overall effect for either intervention (OR $=1.54 ; 95 \% \mathrm{CI}$ : 0.65 , 3.60; $P=0.32 ; I^{2}=0 \%$ [fixed effects]). For renal failure, there were nine events in the angiography group and 21 in the

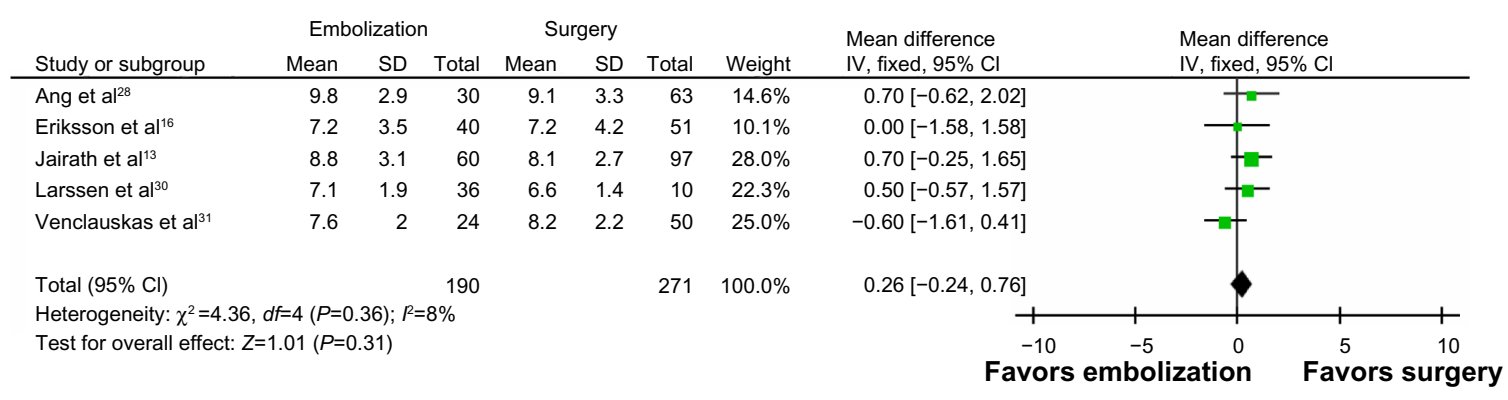

Figure 3 Pooled mean differences in hemoglobin levels preprocedure, comparing TAE and surgery.

Abbreviations: $\mathrm{Cl}$, confidence interval; $d f$, degrees of freedom; IV, initialization vector; SD, standard deviation; TAE, transarterial embolization. 


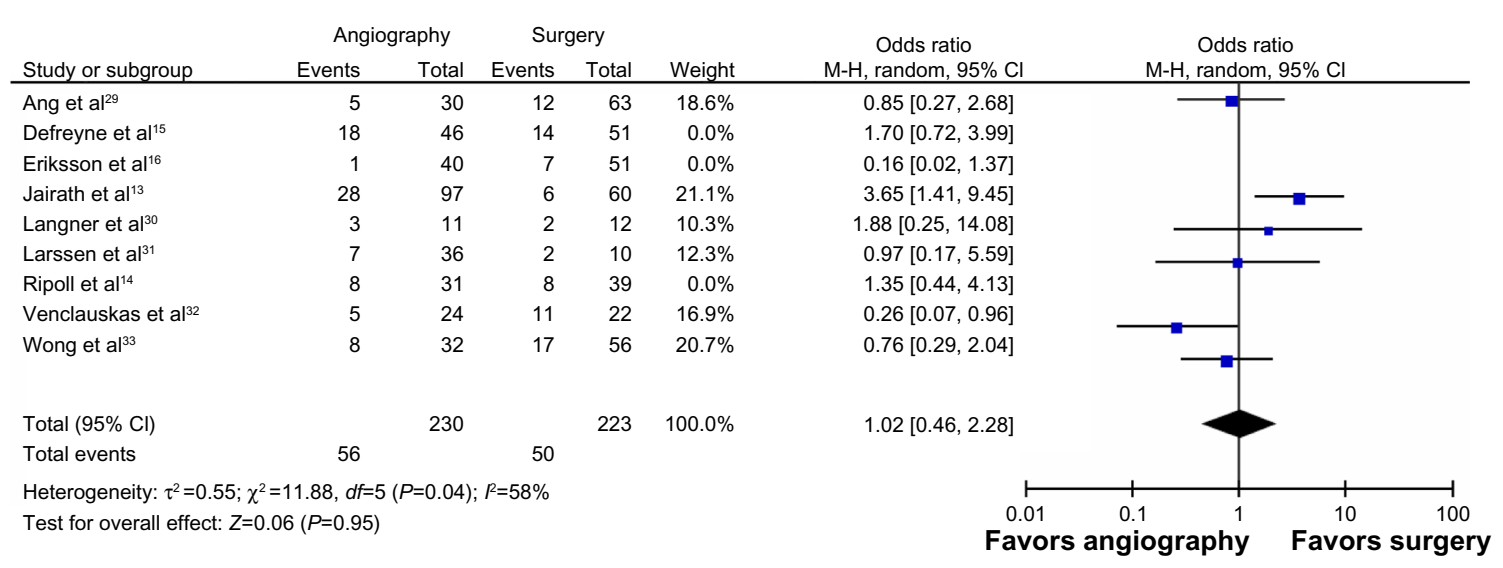

Figure 4 Forest plot of rates of mortality, comparing TAE versus surgery.

Abbreviations: $\mathrm{Cl}$, confidence interval; $d f$, degrees of freedom; $\mathrm{M}-\mathrm{H}$, Mantel-Haenszel; TAE, transarterial embolization.

surgery group, but no effect was seen for either intervention $\left(\mathrm{OR}=0.78 ; 95 \%\right.$ CI: $0.34,1.81 ; P=0.56 ; I^{2}=0 \%$ [fixed effects]). For stroke there were four events in the angiography group and eleven in the surgery group, with no overall effect seen ( $\mathrm{OR}=0.66 ; 95 \%$ CI: $0.20,2.18 ; P=0.57 ; P^{2}=0 \%$ [fixed effects]).

\section{Sensitivity analysis}

A sensitivity analysis was performed separately for each outcome. Analyses for the primary outcomes, mortality and rebleeding rates, demonstrated no significant change to the overall estimate with sequential removal of studies, starting with the largest study.

In order to ascertain whether the age of the study had an impact on the rebleeding and mortality rates observed, the oldest studies (recruitment starting prior to 2000) were removed sequentially. For mortality rates, sequential and simultaneous removal of Defreyne et al, ${ }^{15}$ Eriksson et al, ${ }^{16}$ and Ripoll et a ${ }^{14}$ had no effect on mortality rates. Separate sequential removal of Jairaith et $\mathrm{al}^{13}$ and then Ripoll et a $\mathrm{l}^{14}$ also did not affect the mortality rate. For rebleeding rates, sequential removal of Defreyne et al, ${ }^{15}$ Eriksson et al, ${ }^{16}$ and Ripoll et $\mathrm{a}^{14}$ had no effect on rebleeding rates, but simultaneous removal of all three studies rendered the rates of rebleeding nonsignificant ( $\mathrm{OR}=0.55 ; 95 \% \mathrm{CI}$ : $0.23,1.33 ; P=0.09 ; I^{2}=50 \%$ [random effects]), although there was still a trend towards reduced rebleeding after surgery.

For the secondary outcomes, length of stay, complications (pneumonia, MI, stroke, and renal failure), and preprocedure hemoglobin, there was also no significant change with the sequential removal of studies. Sensitivity analysis for age and coagulopathy demonstrated significant changes in the combined effect size with removal of studies. For age, removal of Jairath et $\mathrm{a}^{13}$ led to a significant difference in age (mean difference $=5.16$ years; $95 \%$ CI: 1.30, 9.02 days; $P=0.009 ; I^{2}=52 \%$ [random effects]). For coagulopathy, removal of Jairath et a ${ }^{13}$ led to overall nonsignificance $(\mathrm{OR}=2.06 ; 95 \% \mathrm{CI}: 0.94,4.50 ; P=0.07$; $I^{2}=65 \%$ [random effects]).

\begin{tabular}{|c|c|c|c|c|c|}
\hline \multirow[b]{2}{*}{ Study or subgroup } & \multicolumn{2}{|c|}{ Embolization } & \multicolumn{2}{|c|}{ Surgery } & \multirow[b]{2}{*}{ Weigh } \\
\hline & Events & Total & Events & Total & \\
\hline Ang et $\mathrm{al}^{29}$ & 14 & 30 & 8 & 63 & 15. \\
\hline Defreyne et al ${ }^{15}$ & 20 & 46 & 4 & 51 & 13. \\
\hline Eriksson et al ${ }^{16}$ & 10 & 40 & 9 & 51 & \\
\hline Jairath et $\mathrm{l}^{13}$ & 6 & 60 & 0 & 0 & \\
\hline Langner et $\mathrm{al}^{30}$ & 3 & 11 & 2 & 12 & \\
\hline Larssen et $\mathrm{al}^{31}$ & 3 & 36 & 2 & 10 & \\
\hline Ripoll et al ${ }^{14}$ & 9 & 31 & 9 & 39 & \\
\hline Venclauskas et $\mathrm{al}^{32}$ & 3 & 24 & 4 & 50 & 10. \\
\hline Wong et $\mathrm{a}^{\mathbf{l}^{33}}$ & 10 & 32 & 14 & 56 & 16. \\
\hline Total $(95 \% \mathrm{Cl})$ & & 310 & & 332 & 100. \\
\hline Total events & 78 & & 52 & & \\
\hline
\end{tabular}

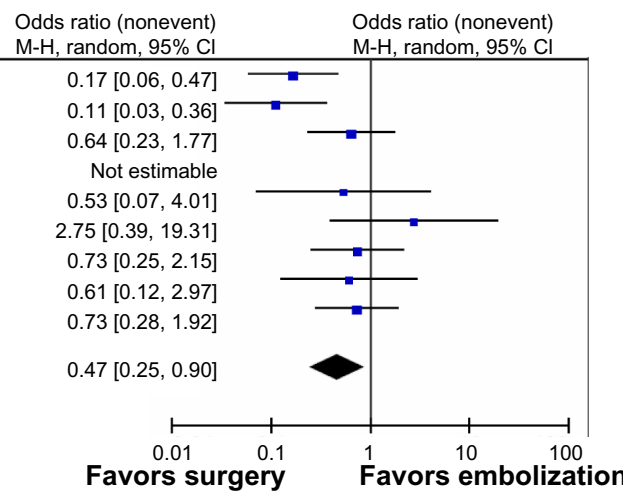

Figure 5 Forest plot of rates of rebleeding after therapy, comparing TAE versus surgery.

Abbreviations: $\mathrm{Cl}$, confidence interval; $d f$, degrees of freedom; $\mathrm{M}-\mathrm{H}$, Mantel-Haenszel; TAE, transarterial embolization. 


\section{Conclusion}

TAE has been increasingly adopted as a treatment for NVUGB that has failed initial endoscopic management, particularly in elderly and frail patients. Although TAE is typically chosen in older patients who have high operative risk (medical comorbidities or older age), our meta-analysis found a nonsignificant trend towards older patients. The only other baseline statistically significant differences seen in patients with TAE were in the frequency of ischemic heart disease and coagulopathy, which were higher in the TAE group. This undoubtedly reflects the preference of the treating clinicians to avoid emergency surgery in patients with severe ischemic heart disease. This was undoubtedly a significant potential source of bias in this study as it is possible that patients enrolled into the TAE arm of the study may have been selected on the basis of their significant comorbidity. In the absence of patient-level data, it is impossible to gauge the effects of the morbidity of individual patients across the studies. Also, patients with coagulopathy who either had a significant bleeding episode or who were on oral anticoagulation for medical reasons could also be a source of bias as these patients may have preferentially undergone TAE rather than surgery. There is no clear evidence to support or refute this hypothesis in the studies analyzed here. None of the studies included had data available to understand the decision-making process involved in selecting each intervention. Another important factor is the age of the studies in this meta-analysis. The earliest of these studies recruited patients from 1986, and both endoscopic and surgical practice have changed markedly since this point, and this will inevitably lead to bias. In our sensitivity analysis, there was no difference in mortality by removing the oldest studies. The differences in rebleeding rates seen between surgery and TAE disappeared when the three oldest studies were removed; however, the trend towards lower rebleeding rates following surgery remained. Of note are the differing durations of embolization vs surgery in terms of operative time. The time taken to arrest hemorrhage would undoubtedly affect outcomes, although this was not measured in any of the studies examined.

We found higher rates of rebleeding in the group treated with TAE. There are several possible explanations for this. One strong factor is the rich collateral blood supply of the gastroduodenal artery, which includes blood supply from other vessels, including the pancreaticoduodenal and superior mesenteric artery branches, and gastroepiploic vessels. This means that coiling of the gastroduodenal artery from the coeliac axis alone may be inadequate to control duodenal ulcer bleeding as the gastroduodenal artery can then be back filled from other collateral branches of the superior mesenteric artery. It is also possible that the local vasoconstriction occurring in critically ill and hypovolemic patients leads to the appearance of cessation of bleeding during TAE but that following volume restoration, rebleeding occurs as the vessel expands to normal size and the embolized coils no longer "fit." 17

Another explanation could be related to the baseline difference we found in the rates of coagulopathy between the two groups. The embolization group had a higher rate of coagulopathy, which has been shown to be associated with an OR of hemostatic failure of between 2.9 and 19.6 in some studies. ${ }^{18-20}$ There was no data describing how coagulopathy was treated in any of the studies. However, meta-regression of the available data did not demonstrate a significant interaction between coagulopathy and rates of rebleeding. We acknowledge that our meta-regression was underpowered, featuring only eight studies, which makes the evidence for this inconclusive. Previous studies have suggested that the earlier hemorrhage is controlled, the less need for large-volume blood transfusion with its associated coagulopathy, and subsequent organ failure and poor outcome are potentially avoided. ${ }^{21}$

Complications of TAE appeared to be underreported in the studies we analyzed, with none of the studies reporting any ischemic complications. Although the upper GI tract usually has a rich collateral blood supply, other studies have shown ischemic complications to occur in between $7 \%$ and $16 \%$ of cases. ${ }^{22,23}$ These can either present acutely, with GI necrosis, or later, with ischemic duodenal stenosis. Other reported complications of TAE include access site arterial trauma, such as intimal dissection or pseudoaneurysm formation, contrast-induced nephropathy, and embolization of nontarget vessels.

We found no differences in the mortality between the embolization and surgery groups, despite higher rates of rebleeding in the embolization group. We accept there are baseline differences in the groups and that there may have been a selection bias towards entering patients with more comorbidities into the TAE group. The evidence regarding comorbidities in these studies is limited; however, there was no clear evidence that there was increased comorbidity in the TAE group. It is possible that the increased rates of rebleeding seen in the TAE group were due to the increased frailty of these patients, leading to higher rebleeding rates. Causes of mortality after upper GI bleeding are complex. Sung et $\mathrm{al}^{24}$ recently analyzed causes of mortality in 10,428 patients 
who were admitted with peptic ulcer bleeding. They found a $6 \% 30$-day mortality rate, and $80 \%$ of patients died from severe comorbid diseases and not the failure to control hemorrhage. In contrast in a recent population-based study, mortality from all causes was increased compared with matched controls. ${ }^{25}$ Less than half of this risk of excess mortality was related to comorbidity, such as malignancy or cardiovascular disease.

Although this is the largest series that has directly compared the use of surgery or TAE in major upper GI hemorrhage, our results are based on nonrandomized studies of variable quality. Therefore, there are several limitations to our results, caused by potential selection bias, confounding variables, and lack of blinding. A particular weakness is that multiple surgical and radiological techniques, spanning over 25 years of practice, feature in these studies, and this will inevitably cause a degree of heterogeneity of outcome. In the absence of high-quality evidence, our study indicates that there is no difference in mortality between surgery and embolization. This is severely confounded by the selection bias inherent to these types of nonrandomized studies. The increased risk of rebleeding in patients undergoing TAE in this study is probably related to selection bias as well as the inclusion of older studies that were conducted at the time when the technique was in its infancy. We are also concerned about the potential risks of postprocedural ischemic complications. Further research in this area, using standardized interventional radiological techniques and equipment, is clearly needed.

A randomized study comparing TAE and surgery in peptic ulcer bleeding uncontrolled by endoscopy is currently recruiting patients in Hong Kong (ClinicalTrials.gov: NCT00766961). ${ }^{26}$ Its primary outcome is 30-day mortality, and the secondary outcomes are recurrent bleeding, need for further intervention in terms of either surgery or interventional radiology, and postprocedural complications. However, the trial was registered in 2007 and has yet to recruit its target of 184 patients. This could be in part related to problems gaining consent in the emergency situation. Recruitment has been slow (personal communication with study primary investigator), and two other major centers that can offer both treatments are now involved. The possibilities for expanding recruitment to other major centers are limited because there are few hospitals that have rapid access to appropriately experienced interventional radiologists and surgeons who are immediately available to stem refractory hemorrhage. For a RCT to be a success, the interventional suite and the operating theatre would have to be in very close proximity or a multiuse facility developed.

The technological advances in the management of hemorrhage via interventional radiology are improving rapidly, whilst the experience of surgeons in the management of upper GI hemorrhage is dwindling. Over the past few decades the number of patients requiring surgical intervention for upper GI bleeding has decreased enormously. In the 1990s, up to $13 \%$ of patients required surgery to control bleeding from peptic ulcer disease. ${ }^{27}$ However, with improved endoscopic hemostatic techniques (such as heater probe, large volumes of adrenaline injection, and clip application) and intravenous proton pump infusions, the rate of surgical procedures has dropped to less than $2 \%$ in the present day. ${ }^{1,28}$

Until RCT evidence is available, there is no clear evidence to recommend TAE over surgery, and this should be considered as an option in selected cases only, such as for patients unfit for emergency surgery or where specialist surgical skills are lacking. TAE should not be seen as the only firstline option, and surgery is still a valid option for refractory NVUGB that has failed endoscopic management.

\section{Author contributions}

ADB and EAG conceived the study. ADB, HCA, MPD, and SLP were responsible for information synthesis. ADB and HCA performed the statistical analysis. ADB, EAG, HA, MPD, and SLP took part in drafting the article or revising it critically for important intellectual content.

\section{Acknowledgments}

ADB receives funding from the Academy of Medical Sciences/Wellcome Trust and the Cancer Research UK Experimental Cancer Medicine Centre Consortium.

\section{Disclosure}

ADB is funded by a Wellcome Trust Postdoctoral Clinician Scientist Fellowship (102732/Z/13/Z). HA is funded by a National Institute for Health Research (NIHR) School for Primary Care Research (SPCR) Fellowship. The authors report no other conflicts of interest in this work.

\section{References}

1. Hearnshaw SA, Logan RF, Lowe D, Travis SP, Murphy MF, Palmer KR. Acute upper gastrointestinal bleeding in the UK: patient characteristics, diagnoses and outcomes in the 2007 UK audit. Gut. 2011;60(10) 1327-1335.

2. Lau JY, Sung JJ, Lam YH, et al. Endoscopic retreatment compared with surgery in patients with recurrent bleeding after initial endoscopic control of bleeding ulcers. N Engl J Med. 1999;340(10):751-756. 
3. Clarke MG, Bunting D, Smart NJ, Lowes J, Mitchell SJ. The surgical management of acute upper gastrointestinal bleeding: a 12-year experience. Int J Surg. 2010;8(5):377-380.

4. Rosch J, Dotter CT, Brown MJ. Selective arterial embolization. A new method for control of acute gastrointestinal bleeding. Radiology. 1972;102(2):303-306

5. Griffiths EA, Devitt PG, Bright T, Watson DI, Thompson SK. Surgical management of peptic ulcer bleeding by Australian and New Zealand upper gastrointestinal surgeons. ANZ J Surg. 2013;83(3):104-108.

6. Mirsadraee S, Tirukonda P, Nicholson A, Everett SM, McPherson SJ. Embolization for non-variceal upper gastrointestinal tract haemorrhage: a systematic review. Clin Radiol. 2011;66(6):500-509.

7. British Society of Gastroenterology Endoscopy Committee. Non-variceal upper gastrointestinal haemorrhage: guidelines. Gut. 2002;51 Suppl 4:iv1-iv6.

8. Intercollegiate Guidelines Network. Management of Acute Upper and Lower Gastrointestinal Bleeding: A National Clinical Guideline. Edinburgh: Scottish Intercollegiate Guidelines Network; 2008.

9. Barkun AN, Bardou M, Kuipers EJ, et al; International Consensus Upper Gastrointestinal Bleeding Conference Group. International consensus recommendations on the management of patients with nonvariceal upper gastrointestinal bleeding. Ann Intern Med. 2010;152(2):101-113.

10. Dworzynski K, Pollit V, Kelsey A, Higgins B, Palmer K; Guideline Development Group. Management of acute upper gastrointestinal bleeding: summary of NICE guidance. BMJ. 2012;344:e3412.

11. Stang A. Critical evaluation of the Newcastle-Ottawa scale for the assessment of the quality of nonrandomized studies in meta-analyses. Eur J Epidemiol. 2010;25(9):603-605.

12. Liberati A, Altman DG, Tetzlaff J, et al. The PRISMA statement for reporting systematic reviews and meta-analyses of studies that evaluate health care interventions: explanation and elaboration. Ann Intern Med. 2009;151(4):W65-W94.

13. Jairath V, Kahan BC, Logan RF, et al. National audit of the use of surgery and radiological embolization after failed endoscopic haemostasis for non-variceal upper gastrointestinal bleeding. Br J Surg. 2012;99(12): 1672-1680.

14. Ripoll C, Bañares R, Beceiro I, et al. Comparison of transcatheter arterial embolization and surgery for treatment of bleeding peptic ulcer after endoscopic treatment failure. J Vasc Interv Radiol. 2004;15(5): 447-450.

15. Defreyne L, De Schrijver I, Decruyenaere J, et al. Therapeutic decision-making in endoscopically unmanageable nonvariceal upper gastrointestinal hemorrhage. Cardiovasc Intervent Radiol. 2008;31(5): 897-905.

16. Eriksson LG, Ljungdahl M, Sundbom M, Nyman R. Transcatheter arterial embolization versus surgery in the treatment of upper gastrointestinal bleeding after therapeutic endoscopy failure. J Vasc Interv Radiol. 2008;19(10):1413-1418.

17. Pua U. Short- and long-term results of transcatheter embolization for massive arterial hemorrhage from gastroduodenal ulcers not controlled by endoscopic hemostasis. Can J Gastroenterol. 2011;25(12):654.

18. Schenker MP, Duszak R Jr, Soulen MC, et al. Upper gastrointestinal hemorrhage and transcatheter embolotherapy: clinical and technical factors impacting success and survival. J Vasc Interv Radiol. 2001;12(11): 1263-1271.
19. Aina R, Oliva VL, Therasse E, et al. Arterial embolotherapy for upper gastrointestinal hemorrhage: outcome assessment. JVasc Interv Radiol. 2001;12(2):195-200.

20. Encarnacion CE, Kadir S, Beam CA, Payne CS. Gastrointestinal bleeding: treatment with gastrointestinal arterial embolization. Radiology. 1992;183(2):505-508.

21. Cooper GS, Chak A, Way LE, Hammar PJ, Harper DL, Rosenthal GE. Early endoscopy in upper gastrointestinal hemorrhage: associations with recurrent bleeding, surgery, and length of hospital stay. Gastrointest Endosc. 1999;49(2):145-152.

22. Poultsides GA, Kim CJ, Orlando R, Peros G, Hallisey MJ, Vignati PV. Angiographic embolization for gastroduodenal hemorrhage: safety, efficacy, and predictors of outcome. Arch Surg. 2008;143(5):457-461.

23. Lang EK. Transcatheter embolization in management of hemorrhage from duodenal ulcer: long-term results and complications. Radiology. 1992;182(3):703-707.

24. Sung JJ, Tsoi KK, Ma TK, Yung MY, Lau JY, Chiu PW. Causes of mortality in patients with peptic ulcer bleeding: a prospective cohort study of 10,428 cases. Am J Gastroenterol. 2010;105(1):84-89.

25. Crooks CJ, Card TR, West J. Excess long-term mortality following non-variceal upper gastrointestinal bleeding: a population-based cohort study. PLoS Med. 2013;10(4):e1001437.

26. Chinese University of Hong Kong. TAE and Surgery in Patients With Peptic Ulcer Bleeding Uncontrolled by Endoscopic Therapy. Available from: http://clinicaltrials.gov/show/NCT00766961. NLM identifier: NCT00766961. Accessed February 18, 2014.

27. Kubba AK, Choudari C, Rajgopal C, Palmer KR. The outcome of urgent surgery for major peptic ulcer haemorrhage following failed endoscopic therapy. Eur J Gastroenterol Hepatol. 1996;8(12):1175-1178.

28. Halland M, Young M, Fitzgerald MN, Inder K, Duggan JM, Duggan A. Characteristics and outcomes of upper gastrointestinal hemorrhage in a tertiary referral hospital. Dig Dis Sci. 2010;55(12):3430-3435.

29. Ang D, Teo EK, Tan A, et al. A comparison of surgery versus transcatheter angiographic embolization in the treatment of nonvariceal upper gastrointestinal bleeding uncontrolled by endoscopy. Eur J Gastroenterol Hepatol. 2012;24(8):929-938.

30. Langner I, Langner S, Partecke LI, et al. Acute upper gastrointestinal hemorrhage: is a radiological interventional approach an alternative to emergency surgery? Emerg Radiol. 2008;15(6):413-419.

31. Larssen L, Moger T, Bjørnbeth BA, Lygren I, Kløw NE. Transcatheter arterial embolization in the management of bleeding duodenal ulcers: a 5.5-year retrospective study of treatment and outcome. Scand J Gastroenterol. 2008;43(2):217-222.

32. Venclauskas L, Bratlie SO, Zachrisson K, Maleckas A, Pundzius J, Jönson C. Is transcatheter arterial embolization a safer alternative than surgery when endoscopic therapy fails in bleeding duodenal ulcer? Scand J Gastroenterol. 2010;45(3):299-304.

33. Wong TC, Wong KT, Chiu PW, et al. A comparison of angiographic embolization with surgery after failed endoscopic hemostasis to bleeding peptic ulcers. Gastrointest Endosc. 2011;73(5):900-908. 


\section{Supplementary material}

Table SI Newcastle-Ottawa quality assessment scale table

\begin{tabular}{|c|c|c|c|c|c|}
\hline Study & $\begin{array}{l}\text { Selection } \\
\text { (out of } 4 \text { ) }\end{array}$ & $\begin{array}{l}\text { Comparability } \\
\text { (out of } 2 \text { ) }\end{array}$ & $\begin{array}{l}\text { Outcome } \\
\text { (out of } 3 \text { ) }\end{array}$ & $\begin{array}{l}\text { Total } \\
\text { (out of } 9 \text { ) }\end{array}$ & $\begin{array}{l}\text { Overall } \\
\text { rating }\end{array}$ \\
\hline Ang et $\mathrm{al}^{\prime}$ & 3 & 0 & 2 & 5 & Adequate \\
\hline Defreyne et $\mathrm{al}^{2}$ & 3 & 0 & 2 & 5 & Adequate \\
\hline Eriksson et $\mathrm{al}^{3}$ & 3 & 0 & 2 & 5 & Adequate \\
\hline Jairath et $\mathrm{al}^{4}$ & 3 & 0 & 2 & 5 & Adequate \\
\hline Langner et $\mathrm{al}^{5}$ & 3 & 0 & 1 & 4 & Adequate \\
\hline Larssen et $\mathrm{al}^{6}$ & 3 & 0 & 2 & 5 & Adequate \\
\hline Ripoll et $\mathrm{al}^{7}$ & 3 & 0 & 2 & 5 & Adequate \\
\hline Venclauskas et al ${ }^{8}$ & 3 & 0 & 2 & 5 & Adequate \\
\hline Wong et $\mathrm{al}^{9}$ & 3 & 0 & 2 & 5 & Adequate \\
\hline
\end{tabular}

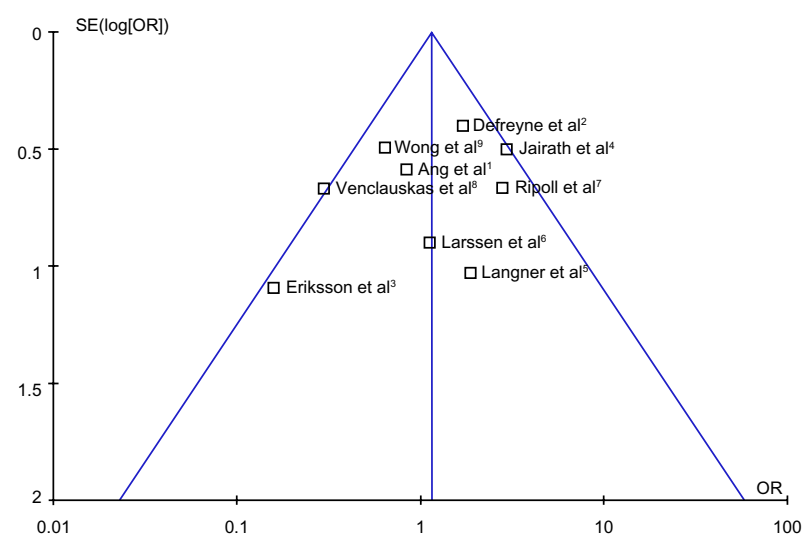

Figure SI Funnel plot of mortality rates in studies analyzed. Abbreviations: OR, odds ratio; SE, standard error.

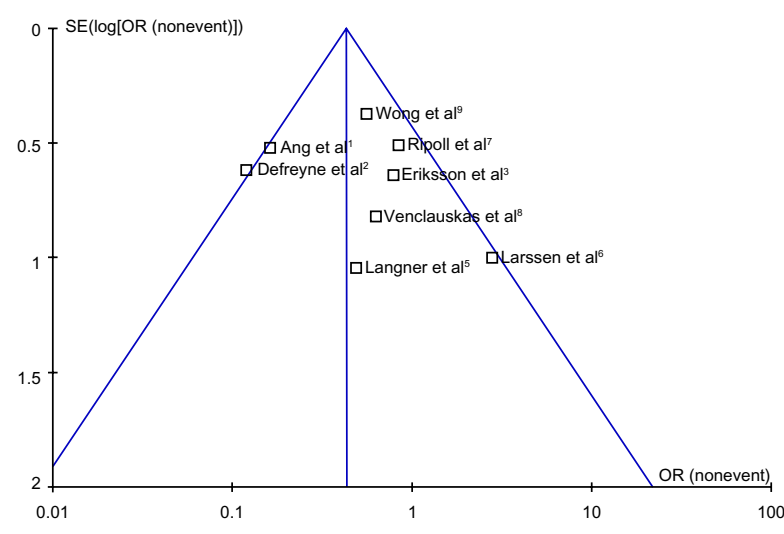

Figure S2 Funnel plot of rebleeding rates in studies analyzed. Abbreviations: OR, odds ratio; SE, standard error.

Table S2 Table of meta-analyzed preprocedure comorbidities

\begin{tabular}{lllllll}
\hline Comorbidity & $\begin{array}{l}\text { Number } \\
\text { studies }\end{array}$ & OR & $\mathbf{9 5 \% ~ C l}$ & P-value & $\mathbf{I}^{\mathbf{2}}$ & Heterogeneity \\
\hline Ischemic heart disease & 6 & 1.99 & $1.33,2.98$ & 0.0008 & $67 \%$ & High \\
Diabetes & 4 & 1.19 & $0.66,2.15$ & 0.56 & $38 \%$ & Moderate \\
Renal disease & 6 & 1.86 & $0.98,3.53$ & 0.06 & $0 \%$ & Low \\
Respiratory disease & 6 & 1.31 & $0.81,2.12$ & 0.28 & $0 \%$ & Low \\
Coagulopathy & 3 & 2.23 & $1.29,3.87$ & 0.004 & $33 \%$ & Moderate \\
\hline
\end{tabular}

Abbreviations: $\mathrm{Cl}$, confidence interval; $\mathrm{OR}$, odds ratio. 
Table S3 Therapy for rebleeding after initial TAE or surgery

\begin{tabular}{|c|c|c|c|c|c|c|c|c|c|c|}
\hline \multirow[t]{2}{*}{ Study } & \multicolumn{2}{|l|}{ Initial failures } & \multicolumn{2}{|c|}{ Repeat TAE } & \multicolumn{2}{|c|}{ Endoscopy } & \multicolumn{2}{|l|}{ Surgery } & \multicolumn{2}{|l|}{ Not done } \\
\hline & $\begin{array}{l}\text { TAE } \\
\text { (n/total) }\end{array}$ & $\begin{array}{l}\text { Surgery } \\
\text { (n/total) }\end{array}$ & $\begin{array}{l}\text { TAE } \\
\text { (n/total) }\end{array}$ & $\begin{array}{l}\text { Surgery } \\
\text { (n/total) }\end{array}$ & $\begin{array}{l}\text { TAE } \\
\text { (n/total) }\end{array}$ & $\begin{array}{l}\text { Surgery } \\
\text { (n/total) }\end{array}$ & $\begin{array}{l}\text { TAE } \\
\text { (n/total) }\end{array}$ & $\begin{array}{l}\text { Surgery } \\
\text { (n/total) }\end{array}$ & $\begin{array}{l}\text { TAE } \\
\text { (n/total) }\end{array}$ & $\begin{array}{l}\text { Surgery } \\
\text { (n/total) }\end{array}$ \\
\hline Ang et al' & $14 / 30(46.7 \%)$ & $8 / 63(12.6 \%)$ & $7 *$ & 4 & 4 & - & 3 & I & 3 & 3 \\
\hline Defreyne et $\mathrm{al}^{2}$ & $20 / 46(43.5 \%)$ & $|3 / 5|$ (25.5\%) & - & I & 5 & 8 & 15 & 3 & - & - \\
\hline Eriksson et al ${ }^{3}$ & $10 / 40$ (25.0\%) & $9 / 51$ (17.6\%) & 5 & 8 & - & - & 5 & I & - & - \\
\hline Jairath et $\mathrm{al}^{4}$ & $6 / 97(6.2 \%)$ & - & - & - & - & - & 6 & - & - & - \\
\hline Langner et $\mathrm{al}^{5}$ & $3 / 11(27.3 \%)$ & $2 / 12(16.7 \%)$ & - & I & 1 & I & 2 & - & - & - \\
\hline Larssen et $\mathrm{al}^{6}$ & $3 / 36(8.3 \%)$ & $2 / 10(20.0 \%)^{* *}$ & - & $?$ & - & $?$ & 3 & $?$ & - & $?$ \\
\hline Ripoll et $\mathrm{al}^{7}$ & $9 / 31$ (29.0\%) & $9 / 39(23.1 \%)$ & - & - & - & - & 5 & 9 & 4 & - \\
\hline Venclauskas et $\mathrm{a}^{8}$ & $3 / 24(12.5 \%)$ & $4 / 50(8.0 \%)$ & - & - & I & I & 2 & 3 & - & - \\
\hline Wong et $\mathrm{al}^{9}$ & I I/32 (34.4\%) & $7 / 56(12.5 \%)$ & - & 4 & 8 & 2 & 3 & I & - & - \\
\hline
\end{tabular}

Notes: * Of these seven in Ang et al: only one patient was successfully embolized; two patients underwent repeat endoscopy; two underwent repeat TAE with success, and two underwent surgical intervention; **of these two patients, it was not specified in the paper what therapy they received for rebleeding after surgery. Abbreviation: TAE, transarterial embolization.

\section{Reference}

1. Ang D, Teo EK, Tan A, etal. A comparison of surgery versus transcatheter angiographic embolization in the treatment of nonvariceal upper gastrointestinal bleeding uncontrolled by endoscopy. Eur J Gastroenterol Hepatol. 2012;24(8):929-938.

2. Defreyne L, De Schrijver I, Decruyenaere J, etal. Therapeutic decisionmaking in endoscopically unmanageable nonvariceal upper gastrointestinal hemorrhage. Cardiovasc Intervent Radiol. 2008;31(5):897-905.

3. Eriksson LG, Ljungdahl M, Sundbom M, Nyman R. Transcatheter arterial embolization versus surgery in the treatment of upper gastrointestinal bleeding after therapeutic endoscopy failure. J Vasc Interv Radiol. 2008;19(10):1413-1418.

4. Jairath V, Kahan BC, Logan RF, etal. National audit of the use of surgery and radiological embolization after failed endoscopic haemostasis for non-variceal upper gastrointestinal bleeding. Br J Surg. 2012;99(12): 1672-1680

5. Langner I, Langner S, Partecke LI, etal. Acute upper gastrointestinal hemorrhage: is a radiological interventional approach an alternative to emergency surgery? Emerg Radiol. 2008;15(6):413-419.
6. Larssen L, Moger T, Bjørnbeth BA, Lygren I, Kløw NE. Transcatheter arterial embolization in the management of bleeding duodenal ulcers: a 5.5-year retrospective study of treatment and outcome. Scand J Gastroenterol. 2008;43(2):217-222.

7. Ripoll C, Bañares R, Beceiro I, etal. Comparison of transcatheter arterial embolization and surgery for treatment of bleeding peptic ulcer after endoscopic treatment failure. J Vasc Interv Radiol. 2004;15(5): $447-450$

8. Venclauskas L, Bratlie SO, Zachrisson K, Maleckas A, Pundzius J, Jönson C. Is transcatheter arterial embolization a safer alternative than surgery when endoscopic therapy fails in bleeding duodenal ulcer? Scand J Gastroenterol. 2010;45(3):299-304.

9. Wong TC, Wong KT, Chiu PW, etal. A comparison of angiographic embolization with surgery after failed endoscopic hemostasis to bleeding peptic ulcers. Gastrointest Endosc. 2011;73(5):900-908.
Clinical and Experimental Gastroenterology

\section{Publish your work in this journal}

Clinical and Experimental Gastroenterology is an international, peerreviewed, open access journal, publishing all aspects of gastroenterology in the clinic and laboratory, including: Pathology, pathophysiology of gastrointestinal disease; Investigation and treatment of gastointestinal disease; Pharmacology of drugs used in the alimentary tract;

\section{Dovepress}

Immunology/genetics/genomics related to gastrointestinal disease. This journal is indexed on CAS. The manuscript management system is completely online and includes a very quick and fair peer-review system. Visit http://www.dovepress.com/testimonials.php to read real quotes from published authors. 